\title{
Correction to: Optimal discrete search with technological choice
}

\author{
Joseph B. Kadane ${ }^{1}$
}

Published online: 31 August 2021

(c) Springer-Verlag GmbH Germany, part of Springer Nature 2021

\section{Correction to: Math Meth Oper Res (2015) 81:317-336 https://doi.org/10.1007/s00186-015-0499-8}

Kadane, J.B. (2015). "Optimal Discrete Search with Technological Choice," Mathematical Methods of Operations Research, 81 (\#3), 317-336.

I am indebted to Dr. Jake Clarkson of Lancaster University for the following corrections:

(1) Theorem 1 requires the assumption that $\alpha>0$.

(2) In the statement of Lemma 2, "non-increasing" should be "non-decreasing" and the inequalities stated in the statement should be reversed. Theorem 1 states this material correctly.

(3) Theorem 3 concerns optimal strategies in the problem of minimizing expected cost. Dr. Clarkson provided me with a two-location, two-technology counter example to (a) in Theorem 3, where the unique optimal search strategy does not maximize equation (30) in Theorem 3 at every stage. One of the locations has $\alpha=0$ (zero overlook probability). See Section 4 (A Special Case with Two Boxes) of Clarkson et al. (2020) for the aforementioned counter example. In general, Clarkson et al. (2020) studies the two-technology, use-independent problem where the expected cost is minimized.

The original article can be found online at https://doi.org/10.1007/s00186-015-0499-8.

Joseph B. Kadane

kadane@stat.cmu.edu

1 Department of Statistics, Carnegie Mellon University, Pittsburgh, PA 15213, USA 


\section{References}

Clarkson J, Glazebrook KD, Lin KY (2020) Fast or slow: search in discrete locations with two search modes. Oper Res 68(2):552-571

Publisher's Note Springer Nature remains neutral with regard to jurisdictional claims in published maps and institutional affiliations. 